\title{
Oxidation of Valine by N-Bromophthalimide in Presence of Chloro- Complex of Pd(II) as Homogenous Catalyst: A Kinetic and Mechanistic Study
}

\author{
Ajaya Kumar Singh ${ }^{*},{ }^{1}$, Bhawana Jain ${ }^{1}$, Reena Negi ${ }^{1}$, Yokraj Katre ${ }^{2}$, S.P. Singh ${ }^{3}$ \\ ${ }^{I}$ Department of Chemistry, Govt. V.Y.T. PG. Autonomous College Durg (C.G.), India \\ ${ }^{2}$ Department of Chemistry, Kalyan Mahavidyalaya, Bhilai Nagar, Sect-7, Bhilai, India \\ ${ }^{3}$ Department of Applied Chemistry, Graduate School of Engineering, Osaka University, Suita, Japan
}

\begin{abstract}
Kinetics of Pd(II) catalyzed oxidation of valine has been studied by N-bromophthalimide (NBP) in acidic medium at $303 \mathrm{~K}$. The reaction follows first order kinetics with respect to [Pd(II)] while negative effect was observed for the variation of $\left[\mathrm{H}^{+}\right]$on the rate of reaction. The reaction exhibits first order kinetics with respect to [NBP] at its lower concentrations and tends towards zero order at its higher concentrations. Rate of reaction exhibits zero order and fractional order kinetics with respect to [valine] and $\left[\mathrm{Cl}^{-}\right]$respectively. $\left[\mathrm{Hg}(\mathrm{OAc})_{2}\right]$, [phthalimide], ionic strength (I) and dielectric constant of the medium did not bring about any significant change on the rate of reaction. The rate constants observed at five different temperatures $(298 \mathrm{~K}-318 \mathrm{~K}$ ) were utilized to calculate the activation parameters. A plausible mechanism has been proposed from the results of kinetic studies, reaction stoichiometry and product analysis.
\end{abstract}

Keywords: Kinetics, oxidation, mechanism, valine, Pd(II) chloride.

\section{INTRODUCTION}

The versatile nature of N-halogeno compounds is due to their ability to act as sources of halonium ions, hypohalite species and nitrogen anions which act as both bases and nucleophiles. N-halocompounds have been used widely as oxidizing and halogenating reagent in organic compounds [1-5]. N-halocompounds, a group of mild oxidizing agents, have been extensively used for catalyzed [6-8] and uncatalyzed [9-12] oxidation of variety of organic compounds. Nbromophthalimide (NBP) has recently been developed as an oxidimetric titrant for the determination of certain pharmaceuticals by Abou Ouf et al. [13, 14]. Literature survey revealed that scanty work has been done on NBP [15-17] which is extremely stable in solid state in the absence of light and moisture. The study of amino acids is one of the most exciting fields of organic chemistry. Amino acid plays a significant role in a number of metabolic reactions like biosynthesis of polypeptide, protein and nucleotides. Thus the mechanism of analogous non-enzymatic chemical processes in the oxidation of amino acids is a potential area for intensive investigation [18]. However there are only few reports available for the oxidation of valine $[19,20]$ by various organic and inorganic oxidants.

Recently, the use of platinum group metal ions such as osmium, ruthenium and iridium either alone or binary mixtures, as catalyst in various redox processes has been attracted considerable interest [21]. Compounds of transition metal ions [22-37] have been extensively used as homoge-

*Address correspondence to this author at the Department of Chemistry, Govt. V.Y.T. PG. Autonomous College Durg (C.G.), India;

Tel:+917882223421; E-mail: ajayaksingh_au@yahoo.co.in nous catalysts. An extensive literature survey reveals that no report available on the oxidation kinetics of valine in the presence of Pd(II). Hence we felt it would be worthwhile to investigate the oxidative behavior of $\mathrm{N}$-bromophthalimde (NBP) with valine to explore the kinetics and mechanistic aspects of the $\operatorname{Pd}(\mathrm{II})$ chloride catalyzed reaction. This study will enable to understand the complicated biological reaction in living systems and will also help to understand the catalytic activity of Pd(II) along with oxidative capacity of NBP in acidic medium.

\section{EXPERIMENTAL}

\subsection{Material}

Analytical reagent grade chemicals and triple distilled water were used throughout the investigation. The solution of NBP (Lancaster, 98\%) was prepared in $80 \%$ acetic acid and stored in a black-coated flask to prevent any photochemical deterioration. The prepared solution of NBP was standardized by reported method [38]. The Pd(II) chloride solution was prepared by dissolving a known weight of palladium (II) chloride (S.D. fine) in $\mathrm{HCl}$ of known strength and stored in a black coated bottle to prevent any photochemical deterioration. Standard solution of valine, $\mathrm{KCl}, \mathrm{NaClO}_{4}$ and phthalimide were prepared with triple distilled water. Mercuric acetate (Loba chem., Mumbai, India) solution was acidified with $20 \%$ acetic acid and perchloric acid (GR) was diluted with triple distilled water for the present investigation.

\subsection{Stoichiometry and Product Analysis}

Different ratios of NBP to valine were equilibrated at 303 $\mathrm{K}( \pm 0.1)$ in the presence of requisite amount of perchloric acid, mercuric acetate and acetic acid under the condition of [NBP] $>>$ [valine] for $72 \mathrm{~h}$. Determination of unconsumed 
NBP revealed that more than two moles of NBP were required for the oxidation of each mole of valine as in the following equation.

Valine +2.4 NBP $\longrightarrow$ Products

The products were identified as a mixture of nitrile, aldehyde and trace of ammonia. Nitrile aldehyde and ammonia were identified by the color reaction with hydroxylamine and iron (III) chloride [39], by Schiff's reagent and by Nessler's reagent respectively. The consumption of more than two moles of NBP per mole of amino acid may be due to the reaction of ammonia with NBP and may also be due to the further oxidation of aldehyde.

\subsection{Test for Free Radicals}

To test the presence of free radicals in the reaction, the reaction mixture with acrylamide was placed in an inert atmosphere for $24 \mathrm{hrs}$. When the reaction mixture was diluted with methanol, no precipitate was formed in the reaction mixture. This clearly showed that free radicals are not involved in the redox reaction under investigation.

\subsection{Kinetic Measurements \& Results}

All the kinetic measurements were carried out in a blackcoated vessels at $303 \mathrm{~K}( \pm 0.1)$ and performed under pseudo first order condition with [valine] $>>[\mathrm{NBP}]$. The reaction was initiated by the rapid addition of known amounts of preequilibrated valine to reaction mixture containing the required amount of NBP, perchloric acid, palladium (II) chloride, mercuric acetate, acetic acid and water in glass stoppered pyrex boiling tubes, thermostated at same temperature. The progress of reaction was monitored by iodometric determination of unconsumed [NBP] in known aliquots of the reaction mixtures at different time intervals. For the determination of kinetics of the oxidation of valine by NBP in an aqueous acidic medium in the presence of palladium (II) chloride was investigated at different initial concentration of all the reactants. It was observed that the reaction do not proceed in the absence of $[\mathrm{Pd}(\mathrm{II})]$. The initial rate $(-\mathrm{dc} / \mathrm{dt})$ in each kinetic run was calculated by the slope of tangent drawn at fixed time for the variation of [NBP] while in the variation of other [reactants], tangents drawn at fixed [NBP] which was written as [NBP]* (Fig. 1). The pseudo first order rate constant $\mathrm{k}_{1}$ was calculated as

$$
\mathrm{k}_{1}=\frac{-(\mathrm{dc} / \mathrm{dt})}{[\mathrm{NBP}]^{*}}
$$

Each kinetic run was studied for two half lives of the reaction. The observed rates of reaction were reproducible within $\pm 5 \%$ in replicate kinetic run. The order of reaction in each reactant was determined with the help of log-log plot of $(-\mathrm{dc} / \mathrm{dt}) v s$ concentration of reactant. For the determination of the order of reaction with respect to each reactant, the help of Ostwald's isolation methods in conjuction with Van't Hoff's differntial method has been taken. Considering NBP, valine, $\mathrm{H}^{+}, \mathrm{Pd}(\mathrm{II})$ chloride as the main reactants, the general form of the rate equation for the reaction can be written as

Rate $=\mathrm{k}[\mathrm{NBP}]^{\alpha}[\text { valine }]^{\beta}[\text { catalyst }]^{\gamma}\left[\mathrm{H}^{+}\right]^{\delta}$

Uniform pseudo first order rate constant $\left(\mathrm{k}_{1}\right)$ values of [NBP] from $0.5 \times 10^{-4} \mathrm{M}$ to $4.0 \times 10^{-4} \mathrm{M}$ clearly show that the order with respect to [NBP] is less than unity. This is also obvious from the plot of (-dc/dt) vs [NBP] (Fig. 2, Table 1). The reactions have been studied ten fold variation in [valine] from $0.5 \times 10^{-3} \mathrm{M}$ to $5.0 \times 10^{-3} \mathrm{M}$ at constant concentration of all reactants at $303 \mathrm{~K}$. The rate of reaction was

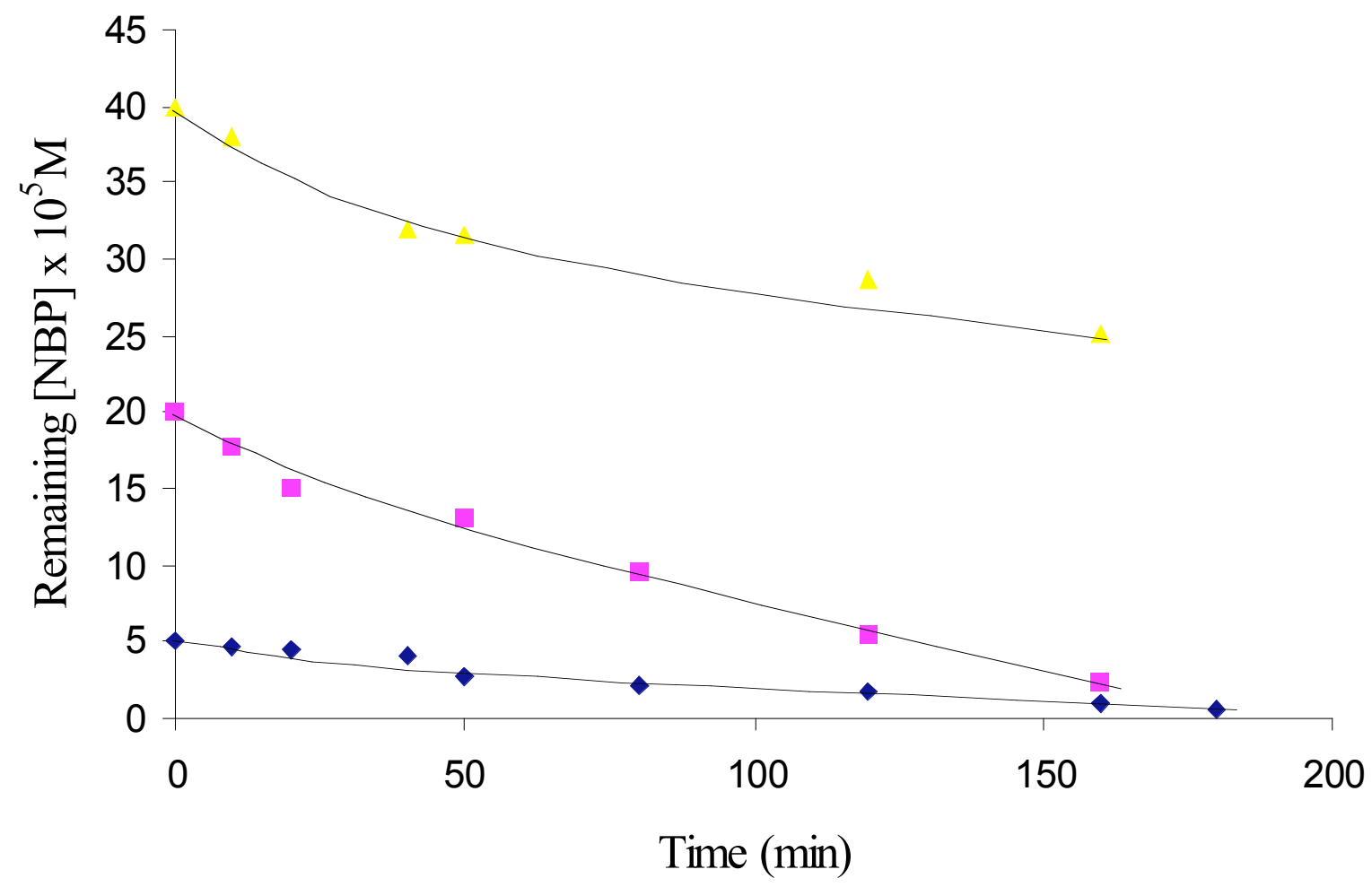

Fig. (1). Plot between unconsumed $[\mathrm{NBP}]$ vs Time at $\mathrm{T}=303 \mathrm{~K}$. [valine] $=2 \times 10^{-3} \mathrm{M},\left[\mathrm{HClO}_{4}\right]=0.5 \mathrm{M},[\mathrm{Pd}(\mathrm{II})]=4.2 \times 10^{-5} \mathrm{M}$, $\left[\mathrm{Hg}(\mathrm{OAc})_{2}\right]=3 \times 10^{-4} \mathrm{M},[\mathrm{KCl}]=1 \times 10^{-4} \mathrm{M}$ and $\mathrm{CH}_{3} \mathrm{COOH}=20 \%$. 
found to be nearly the same for all concentrations of valine, exhibiting zero order kinetics with respect to valine (Table 1). The reaction follows first order kinetics with respect to $[\mathrm{Pd}(\mathrm{II})]$ and this result was further verified by the plot of $\mathrm{dc} / \mathrm{dt} v s[\mathrm{Pd}(\mathrm{II})]$ (Fig. 2, Table 2). On increasing $\left[\mathrm{HClO}_{4}\right]$ the values of reaction rate decreased without following any relationship. This showed negative effect of $\left[\mathrm{H}^{+}\right]$on the rate of reaction (Fig. 3, Table 1). Variation of $\left[\mathrm{Cl}^{-}\right]$ion have positive effect (Fig. 3, Table 2) and the ionic strength of the medium did not affect the rate significantly, indicating involvement of a non-ionic species in the rate determining step. Subsequently the ionic strength of the reaction mixture was not kept constant for kinetic runs. There is no significant effect of increase in concentration of mercuric acetate and phthalimide on rate of reaction. Rate studies were carried out with acetonitrile in different composition (5\%-40\% by volume) in reaction mixture, thereby varying the dielectric constant of the medium. It was found that there is no significant effect of dielectric constant of the medium on the rate of reaction. It was observed that acetonitrile was not oxidized by NBP under the experimental conditions. To determine the activation parameters, the reaction was performed at five different temperatures (298-318K) (Fig. 4, Table 3). Arrhenius plot of $\log \mathrm{k}_{1}$ vs $1 / \mathrm{T}$ was used to calculate activation energy (Ea). On the basis of Ea and with the help of specific rate constant $\left(\mathrm{k}_{\mathrm{r}}\right)$, values of the other activation parameters such as enthalpy of activation $\left(\Delta \mathrm{H}^{\#}\right)$, entropy of activation $\left(\Delta S^{\#}\right)$, Gibb's free energy of activation $\left(\Delta G^{\#}\right)$ and frequency factor (A) were evaluated (Table 3).

Table 1. Effect of [NBP], [Valine] and $\left[\mathrm{H}^{+}\right]$on the Rate of Oxidation of Valine at $303 \mathrm{~K}$

\begin{tabular}{|c|c|c|c|c|}
\hline $\begin{array}{c}\text { [NBP] } \mathbf{~ 1 0} \\
\mathbf{M}\end{array}$ & $\begin{array}{c}\text { [Valine] } \mathbf{x} \mathbf{1 0}^{\mathbf{3}} \\
\mathbf{M}\end{array}$ & $\begin{array}{c}{\left[\mathbf{H}^{+}\right]} \\
\mathbf{M}\end{array}$ & $\begin{array}{c}\mathbf{k}_{\mathrm{gr}} \mathbf{\mathbf { ~ } \mathbf { 1 0 }} \\
\mathbf{s}^{-\mathbf{1}}\end{array}$ & $\begin{array}{c}\mathbf{k}_{\text {cal }} \mathbf{\mathbf { ~ 1 0 }} \\
\mathbf{s}^{-1}\end{array}$ \\
\hline \hline 0.5 & 2.0 & 0.5 & 1.2 & 1.2 \\
1.0 & 2.0 & 0.5 & 1.5 & 1.4 \\
1.5 & 2.0 & 0.5 & 1.9 & 1.7 \\
2.0 & 2.0 & 0.5 & 2.2 & 2.2 \\
2.5 & 2.0 & 0.5 & 2.1 & 2.3 \\
3.0 & 2.0 & 0.5 & 2.3 & 2.1 \\
4.0 & 2.0 & 0.5 & 2.6 & 2.2 \\
2.0 & 0.5 & 0.5 & 2.3 & 2.5 \\
2.0 & 1.0 & 0.5 & 2.1 & 2.3 \\
2.0 & 2.0 & 0.5 & 2.5 & 2.1 \\
2.0 & 3.0 & 0.5 & 2.6 & 2.3 \\
2.0 & 4.0 & 0.5 & 2.2 & 2.3 \\
2.0 & 5.0 & 0.5 & 2.6 & 2.4 \\
2.0 & 2.0 & 0.1 & 10.4 & 11.1 \\
2.0 & 2.0 & 0.2 & 7.3 & 7.2 \\
2.0 & 2.0 & 0.3 & 4.2 & 4.2 \\
2.0 & 2.0 & 0.4 & 2.7 & 2.5 \\
2.0 & 2.0 & 0.5 & 2.2 & 2.1 \\
2.0 & 2.0 & 0.6 & 1.1 & 1.3 \\
2.0 & 2.0 & 0.8 & 0.7 & 0.6 \\
2.0 & 2.0 & 1.0 & 0.5 & 0.5 \\
\hline
\end{tabular}

Solution conditions: $\left[\mathrm{Hg}(\mathrm{OA})_{2}\right]=3 \times 10^{-4} \mathrm{M},[\mathrm{Pd}(\mathrm{II})]=4.2 \times 10^{-5} \mathrm{M},[\mathrm{KCl}]=1 \times 10^{-4}$ $\mathrm{M}, \mathrm{CH}_{3} \mathrm{COOH}=20 \%$.
Table 2. Effect of [KCI], [Pd(II)] and Acetonitrile \% on the Rate of Oxidation of Valine at $303 \mathrm{~K}$

\begin{tabular}{|c|c|c|c|c|}
\hline $\begin{array}{c}{[\mathrm{KCl}] \mathbf{x}} \\
10^{4} \mathbf{M}\end{array}$ & $\begin{array}{c}{[\mathrm{Pd}(\mathrm{II})] \times} \\
10^{5} \mathrm{M}\end{array}$ & $\begin{array}{l}\text { Acetonitrile } \\
\text { by Volume }\end{array}$ & $\underset{\mathrm{s}^{-1}}{\mathrm{k}_{\mathrm{gr}} \times 10^{4}}$ & $\underset{\mathrm{s}^{-1}}{\mathbf{k}_{\text {cal }} \times 10^{4}}$ \\
\hline 1.0 & 4.2 & - & 2.2 & 2.3 \\
\hline 2.0 & 4.2 & - & 2.8 & 2.7 \\
\hline 3.0 & 4.2 & - & 3.3 & 3.2 \\
\hline 4.0 & 4.2 & - & 4.4 & 4.1 \\
\hline 6.0 & 4.2 & - & 5.6 & 5.6 \\
\hline 8.0 & 4.2 & - & 6.6 & 6.7 \\
\hline 10.0 & 4.2 & - & 7.3 & 7.4 \\
\hline 1.0 & 1.0 & - & 0.5 & 0.5 \\
\hline 1.0 & 2.1 & - & 0.9 & 1.0 \\
\hline 1.0 & 3.0 & - & 1.3 & 1.5 \\
\hline 1.0 & 4.2 & - & 2.2 & 2.3 \\
\hline 1.0 & 5.3 & - & 2.8 & 2.7 \\
\hline 1.0 & 6.4 & - & 3.5 & 3.4 \\
\hline 1.0 & 8.6 & - & 5.3 & 5.3 \\
\hline 1.0 & 10.0 & - & 6.7 & 6.6 \\
\hline 1.0 & 4.2 & 0 & 2.5 & 2.3 \\
\hline 1.0 & 4.2 & 5 & 2.1 & 2.6 \\
\hline 1.0 & 4.2 & 10 & 2.2 & 2.1 \\
\hline 1.0 & 4.2 & 15 & 2.1 & 2.4 \\
\hline 1.0 & 4.2 & 20 & 2.2 & 2.3 \\
\hline 1.0 & 4.2 & 25 & 2.3 & 2.3 \\
\hline 1.0 & 4.2 & 30 & 2.5 & 2.2 \\
\hline 1.0 & 4.2 & 40 & 2.2 & 2.4 \\
\hline
\end{tabular}

Solution conditions: $[\mathrm{NBP}]=2 \times 10^{-4} \mathrm{M},[$ valine $]=2 \times 10^{-3} \mathrm{M},\left[\mathrm{H}^{+}\right]=0.5 \mathrm{M}$. $\mathrm{CH}_{3} \mathrm{COOH}=20 \%$.

Table 3. Effect of Temperature and Corresponding Activation Parameters on the Rate of Oxidation of Valine

\begin{tabular}{|c|c|c|}
\hline Temperature K & $\mathbf{k}_{\text {gr }} \mathbf{x} \mathbf{1 0}^{\mathbf{4}} \mathbf{s}^{-1}$ & $\mathbf{k}_{\text {cal }} \mathbf{x} \mathbf{1 0}^{\mathbf{4}} \mathbf{s}^{-1}$ \\
\hline \hline 298 & 1.0 & 1.2 \\
303 & 2.2 & 2.3 \\
308 & 3.7 & 3.8 \\
313 & 5.0 & 5.2 \\
318 & 7.0 & 7.4 \\
Ea $\left(\mathrm{kJ} \mathrm{mol}^{-1)}\right.$ & 57.24 & \\
$\Delta \mathrm{H}^{\#}\left(\mathrm{~kJ} \mathrm{~mol}^{-1}\right)$ & $54.72 \pm 0.06$ & \\
$\Delta \mathrm{S}^{\#}\left(\mathrm{JK} \mathrm{mol}^{-1}\right)$ & $129.6 \pm 1.21$ & \\
$\Delta \mathrm{G}^{\#}\left(\mathrm{~kJ} \mathrm{~mol}^{-1}\right)$ & $15.45 \pm 0.31$ & \\
$\operatorname{log~A}$ & $10.24 \pm 0.19$ & \\
$\mathrm{k}_{\mathrm{r}} \times 10^{4} \mathrm{~s}^{-1}$ & 0.375 & \\
\hline
\end{tabular}

\section{DISCUSSION}

The chemistry of amino acids consist transformation of functional groups already present in these molecule. However, their ions intact with hydrocarbon moieties have not 


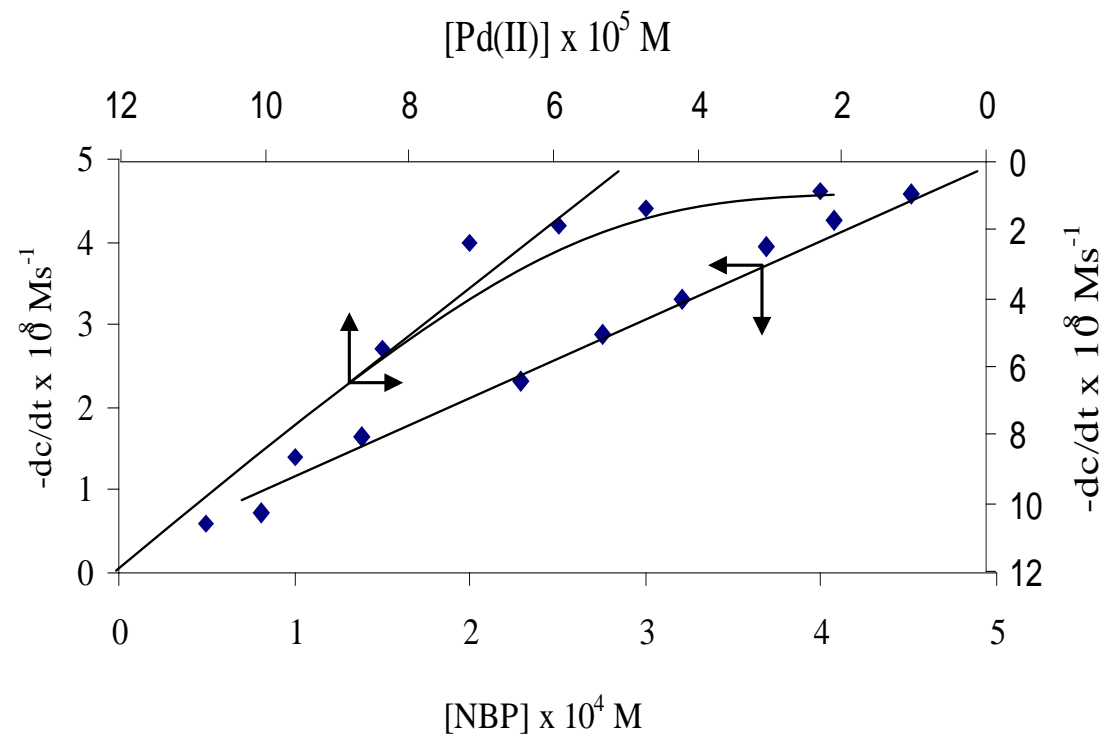

Fig. (2). Plot between rate of reaction (-dc/dt) $v s[\mathrm{NBP}]$ and $[\mathrm{Pd}(\mathrm{II})]$ at $\mathrm{T}=303 \mathrm{~K}$. [valine] $=2 \times 10^{-3} \mathrm{M},\left[\mathrm{HClO}{ }_{4}\right]=0.5 \mathrm{M},\left[\mathrm{Hg}(\mathrm{OAc})_{2}\right]=3 \mathrm{x}$ $10^{-4} \mathrm{M},[\mathrm{KCl}]=1 \times 10^{-4} \mathrm{M}$ and $\mathrm{CH}_{3} \mathrm{COOH}=20 \%$.

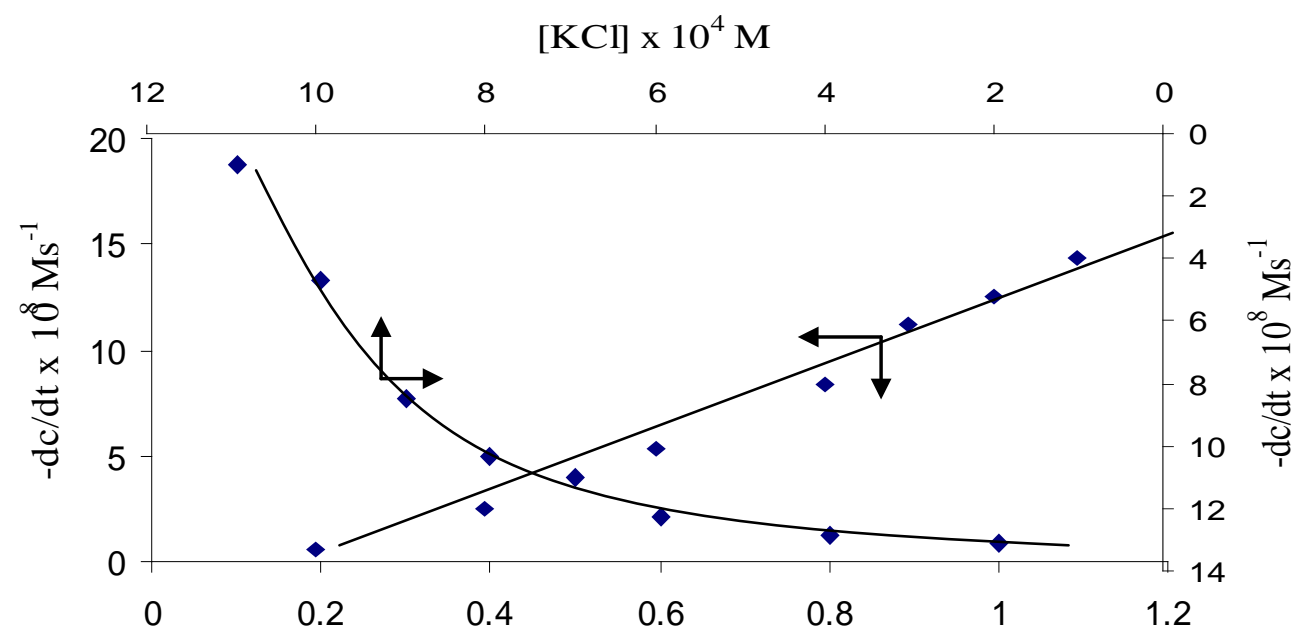

$\left[\mathrm{H}^{+}\right] \mathrm{M}$

Fig. (3). Plot between rate of reaction (-dc/dt) $v s\left[\mathrm{H}^{+}\right]$and $[\mathrm{KCl}]$ at $\mathrm{T}=303 \mathrm{~K}$. $[\mathrm{NBP}]=2 \times 10^{-4} \mathrm{M}$, $[\mathrm{valine}]=2 \times 10^{-3} \mathrm{M},[\mathrm{Pd}(\mathrm{II})]=4.2 \mathrm{x}$ $10^{-5} \mathrm{M},\left[\mathrm{Hg}(\mathrm{OAc})_{2}\right]=3 \times 10^{-4} \mathrm{M}$ and $\mathrm{CH}_{3} \mathrm{COOH}=20 \%$.

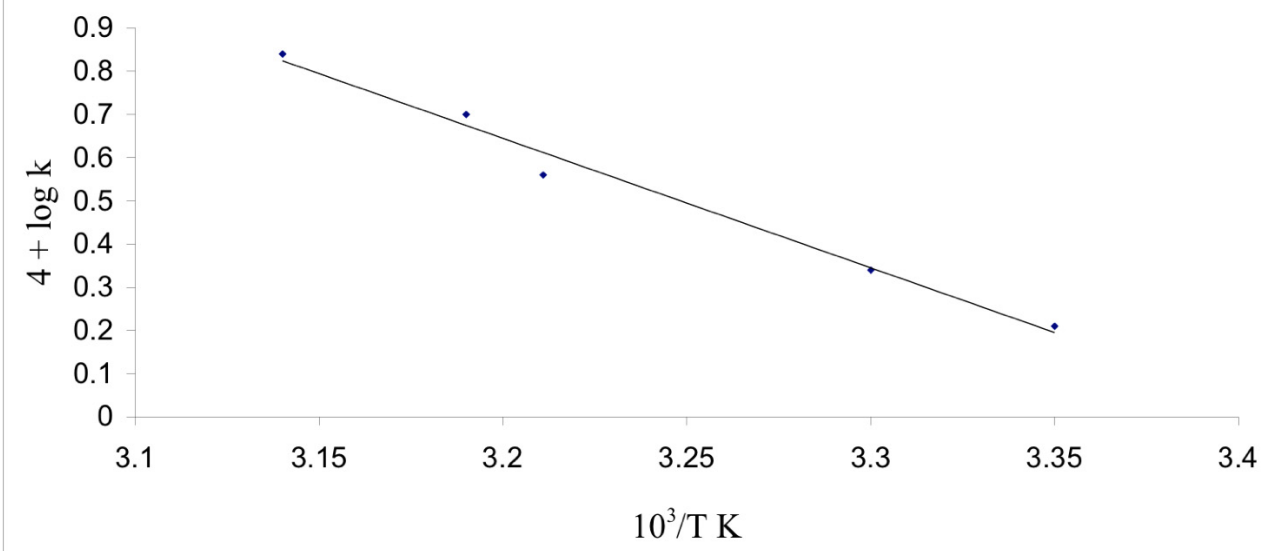

Fig. (4). Plot between rate of reaction log $\mathrm{k} v$ temperature. $[\mathrm{NBP}]=2 \times 10^{-4} \mathrm{M},[$ valine $]=2 \times 10^{-3} \mathrm{M},[\mathrm{Pd}(\mathrm{II})]=4.2 \times 10^{-5} \mathrm{M},\left[\mathrm{Hg}(\mathrm{OAc})_{2}\right]$ $=3 \times 10^{-4} \mathrm{M}$, and $[\mathrm{KCl}]=1 \times 10^{-4} \mathrm{M}$ and $\mathrm{CH}_{3} \mathrm{COOH}=20 \%$. 
been subjected to chemical reaction and the reason for this is obviously the high reactivity of the functional groups relative to inertness of the hydrocarbon chain. The $\alpha$-amino acid is known to exist in the following equilibria in aqueous solution.

$$
\begin{aligned}
& \mathrm{RCHNH}_{2} \mathrm{COOH} \rightleftharpoons \mathrm{RCHNH}_{2} \mathrm{COO}^{-}+\mathrm{H}^{+} \rightleftharpoons \mathrm{RCHNH}_{3} \mathrm{COO}^{-} \\
& \text {Amino acid (S) Anion ( } \left.\left.\mathrm{S}^{-}\right) \quad \text { Zwitter ion ( } \mathrm{S}^{\circ}\right)
\end{aligned}
$$

The dissociation of amino acid depends upon the $\mathrm{pH}$ of the solution. In strongly acidic or strongly alkaline solution, amino acid dissociates as shown in below:

$$
\begin{aligned}
& \stackrel{+}{\mathrm{RCHNH}_{3} \mathrm{COOH}} \underset{+\mathrm{H}^{+}}{\stackrel{-\mathrm{H}^{+}}{\rightleftharpoons}} \mathrm{RCHN}^{+} \mathrm{H}_{3} \mathrm{COO}^{-} \underset{+\mathrm{H}^{+}}{\stackrel{-\mathrm{H}^{+}}{\rightleftharpoons}} \mathrm{RCHNH}_{2} \mathrm{COO}^{-} \\
& \text {Cation }\left(\mathrm{S}^{+} \mathrm{H}\right) \quad \text { Zwitter ion }\left(\mathrm{S}^{\mathrm{O}}\right) \quad \text { Anion }\left(\mathrm{S}^{-}\right)
\end{aligned}
$$

In fact, under the experimental conditions the concentration of anion-form will be very low and the possibility of its participation in the reaction will be least. The possible reactive reducing species may either be the cationic-form or zwitter-ionic form of amino acid. Further, considering $\left(\mathrm{S}^{+} \mathrm{H}\right)$ as the main reactive species the rate law deduced would show a first order dependence in $\left[\mathrm{H}^{+}\right]$contrary to our experimental results. Thus, the only possible active species controlling the rate of oxidation seems to be the zwitter ion $\left(\mathrm{S}^{\circ}\right)$. Hence, $\left(\mathrm{S}^{\mathrm{o}}\right)$ is the main active species was proposed in the following reaction scheme. Under the present experimental conditions, valine exists in the form of zwitter ionic species, $\left(\mathrm{S}^{\circ}\right)$, to an extent of $63 \%$, the remaining $37 \%$ being present in the protonated form, $\left(\mathrm{S}^{+} \mathrm{H}\right)$. The result of oxidation of amino acid by NBP has revealed that reaction has identical kinetics with respect to NBP, several experiment have been carried out with mercuric acetate in the absence of oxidant and was found that reaction did not proceed, this showed that mercuric acetate did not act as an oxidant. Similar reaction was performed in the presence of NBP without catalyst; the reaction did not proceed, suggesting that mercuric acetate only acts as a $\mathrm{Br}^{-}$ion scavenger in the form of $\left[\mathrm{HgBr}_{4}{ }^{2-}\right]$.

\subsection{Reactive Species of NBP}

It has been reported earlier by several workers [40-44] that NBP is good oxidizing and brominating agent. NBP,

\begin{tabular}{|c|c|c|c|c|c|}
\hline NBP & + & $\mathrm{H}_{2} \mathrm{O}$ & $\rightleftharpoons$ & $\mathrm{HOBr}$ & + \\
\hline NBP & + & $\mathrm{H}^{+}$ & & NHP & + \\
\hline NBP & + & $\mathrm{H}^{+}$ & & $(\mathrm{NBPH})^{+}$ & \\
\hline $\mathrm{HOBr}$ & + & $\mathrm{H}^{+}$ & $\rightleftharpoons$ & $\left(\mathrm{H}_{2} \mathrm{OBr}\right)^{+}$ & \\
\hline
\end{tabular}
like other similar $N$-halo imides, may exist in various forms in acidic medium, i.e., free NBP, protonated NBP, $\mathrm{Br}^{+}$, $\mathrm{HOBr},\left(\mathrm{H}_{2} \mathrm{OBr}\right)^{+}$, as per the following equilibria:

When $\left(\mathrm{H}_{2} \mathrm{OBr}\right)^{+}$is taken as reactive species, the rate law obtained shows first order kinetics with respect to hydrogen ion concentrations, contrary to our observed negative fractional order in $\left[\mathrm{HClO}_{4}\right]$. Therefore, the possibility of $\left(\mathrm{H}_{2} \mathrm{OBr}\right)^{+}$and cationic bromine $(\mathrm{Br})^{+}$as reactive species is ruled out. When $\mathrm{HOBr}$ is assumed as the reactive species, the derived rate law failed to explain negligible effect of phthalimide. Hence neither of these species can be considered as the reactive species. Thus, only choice left is NBP, which when considered as the reactive species, leads to a rate law capable of explaining all the kinetic observations and other effects. Hence in the light of kinetic observation, NBP can safely be assumed to be the main reactive species for the present reaction.

\subsection{Reactive Species of Pd(II) Chloride}

The complexes of platinum or palladium group metals are well known. The different possible mononuclear complexes of palladium (II) viz $\left[\mathrm{PdCl}_{3} \mathrm{~L}\right]^{-},\left[\mathrm{PdCl}_{2} \mathrm{~L}_{2}\right],\left[\mathrm{PdClL}_{3}\right]^{+}$ and $\left[\mathrm{PdL}_{4}\right]^{2+}$ ( where $\mathrm{L}$ represent a ligand like amine, phosphine, sulphide) are reported [45]. In most of the studies using $\mathrm{Pd}(\mathrm{II})$ as a homogenous catalyst; it has been employed in the form of $\mathrm{Pd}(\mathrm{II})$ chloride. Palladous chloride [37] is insoluble in aqueous solution but is dissolved in the presence of $\mathrm{Cl}^{-}$. Elding [46] reported that in the presence of chloride ion, palladium chloride exists as $\left[\mathrm{PdCl}_{4}\right]^{2-}$ and in the aqueous solution, it may be further hydrolyzed to $\left[\mathrm{PdCl}_{3}\left(\mathrm{H}_{2} \mathrm{O}\right)\right]^{-}$. The equilibrium constant corresponding to the following equilibrium has been determined by several workers, and all are in good agreement with a value of $\log \beta_{4}$ between 11 and 12 at $25^{0} \mathrm{C}$.

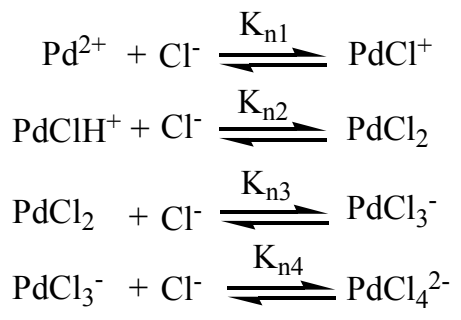

It is reported [29] that $\mathrm{Kn}_{4}$ is probably the most important stability constant for catalytic chemistry. The reported values of $\log \mathrm{Kn}_{1}-\operatorname{logKn_{4}}$ are 4.47, 3.29, 2.41 and 1.37 respectively. According to the following equillibria:

$$
\begin{aligned}
& \mathrm{Pd}^{2+}+4 \mathrm{Cl}^{-} \stackrel{\mathrm{B}_{4}}{=}\left[\mathrm{PdCl}_{4}\right]^{2-} \\
& {\left[\mathrm{PdCl}_{4}\right]^{2-}+\mathrm{H}_{2} \mathrm{O} \stackrel{\mathrm{K}_{\mathrm{h}}}{=}\left[\mathrm{PdCl}_{3}\left(\mathrm{H}_{2} \mathrm{O}\right)\right]^{-}+\mathrm{Cl}^{-}}
\end{aligned}
$$

The reported value of $\log \beta_{4}$ is 11.54 ( $\beta_{4}$ is the equilibrium constant) and value of hydrolytic constant $\left(\mathrm{K}_{\mathrm{h}}\right)$ is $2.50 \mathrm{x}$ $10^{-3}$. The existence of $\mathrm{Pd}(\mathrm{II})$ chloride exclusive in the form of complex $\left[\mathrm{PdCl}_{4}\right]^{2-}$ is also reported by Ayers [47]. In the present investigation, reaction is influenced by $\mathrm{Cl}^{-}$ions, therefore $\left[\mathrm{PdCl}_{3}\right]^{-}$may be considered as reactive species of the $\operatorname{Pd}(\mathrm{II})$.

On the basis of the mechanism in scheme $\mathbf{1}$ and considering the fact that 1 mole of valine is oxidized by 2 moles of NBP. The rate in term of decrease in concentration of NBP can be expressed as:

Rate $=2 \mathrm{k}\left[\mathrm{C}_{4}\right]$

On the basis of equilibrium steps (I) to (VI), eq. (2) to (7) can be obtained in the following forms, respectively:

$$
\mathrm{K}_{1}=\frac{\left[\mathrm{PdCl}_{3}\right]^{-}}{\left[\mathrm{PdCl}_{2}\right] \quad\left[\mathrm{Cl}^{-}\right]}
$$

where $\left[\mathrm{C}_{1}\right]=\left[\mathrm{PdCl}_{2}\right]$

$\left[\mathrm{C}_{2}\right]=\left[\mathrm{PdCl}_{3}\right]$ 


$$
\begin{aligned}
& \text { So }\left[\mathrm{C}_{2}\right]=\mathrm{K}_{1}\left[\mathrm{C}_{1}\right]\left[\mathrm{Cl}^{-}\right] \\
& {\left[\mathrm{PdCl}_{3}\right]^{-}=\mathrm{K}_{1}\left[\mathrm{PdCl}_{2}\right]\left[\mathrm{Cl}^{-}\right]} \\
& {\left[\mathrm{C}_{3}\right]=\mathrm{K}_{2}[\mathrm{NBP}]\left[\mathrm{C}_{2}\right]}
\end{aligned}
$$
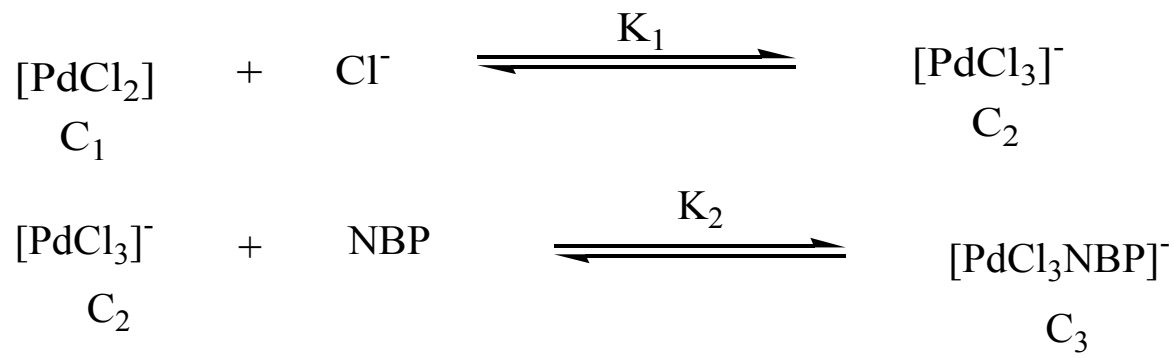

$$
\underset{\mathrm{C}_{3}}{\left[\mathrm{PdCl}_{3} \mathrm{NBP}\right]^{-}}+\mathrm{H}_{2} \mathrm{O} \rightleftharpoons \underset{\mathrm{K}_{3}}{\mathrm{C}_{4}} \underset{\left[\mathrm{PdCl}_{3}(\mathrm{NBP})(\mathrm{OH})\right]^{2-}+\mathrm{H}^{+}}{\rightleftharpoons}
$$
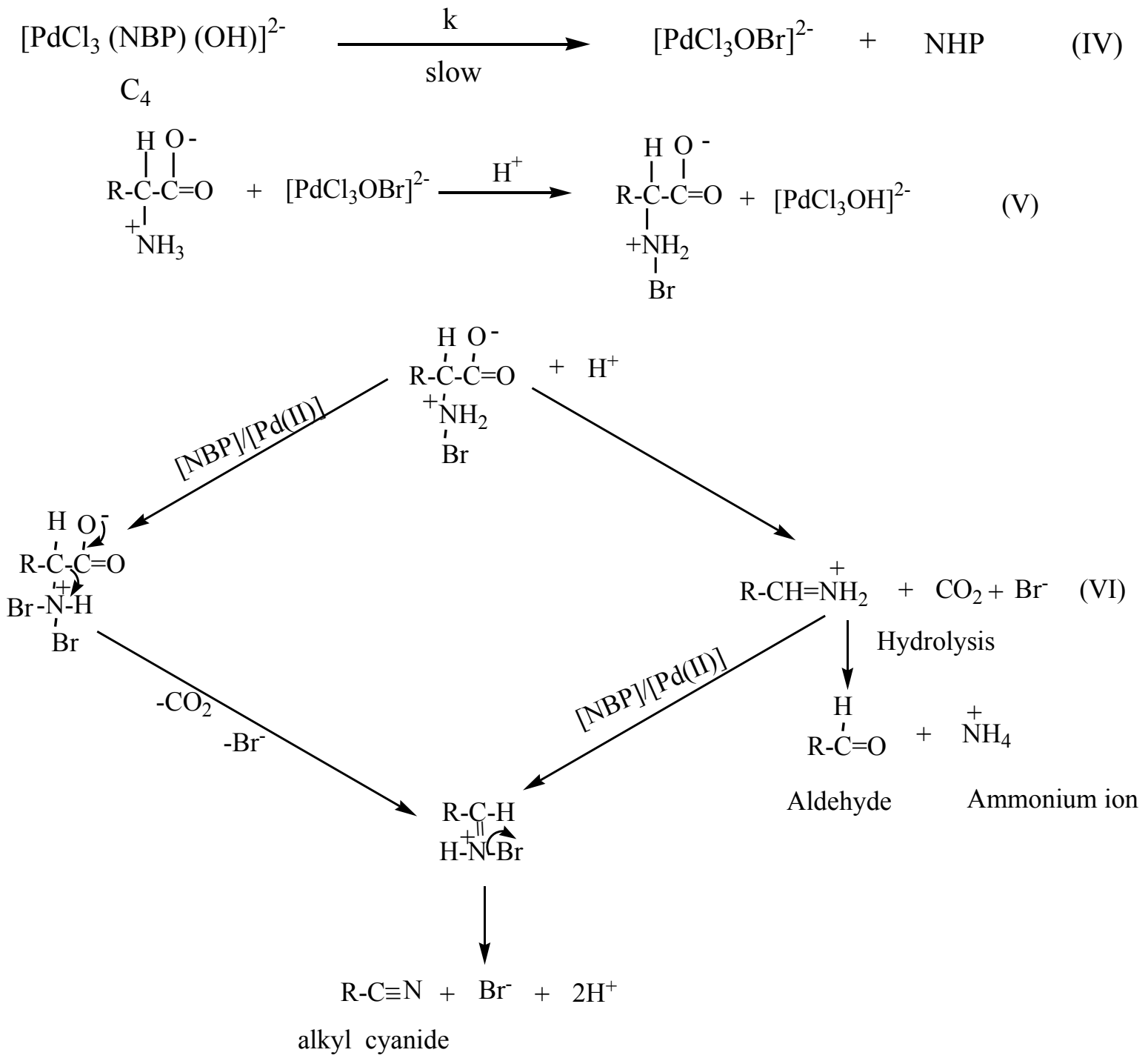

Scheme 1. Reaction scheme. 
$=\underline{\mathrm{K}_{1} \mathrm{~K}_{2} \mathrm{~K}_{3}[\mathrm{NBP}]\left[\mathrm{PdCl}_{2}\right]\left[\mathrm{Cl}^{-}\right]}$

\section{$\left[\mathrm{H}^{+}\right]$}

With the help of Eq. (7) and (1) we can write Eq. (8) as

$\begin{array}{llllll}2 \mathrm{k} & \mathrm{K}_{1} & \mathrm{~K}_{2} & \mathrm{~K}_{3} & {[\mathrm{NBP}} & {\left[\mathrm{PdCl}_{2}\right]}\end{array}\left[\mathrm{Cl}^{-}\right]$

Rate $=$

$\left[\mathrm{H}^{+}\right]$

At any moment of the reaction, the total concentration of $[\mathrm{Pd}(\mathrm{II})]$, i.e. $[\mathrm{Pd}(\mathrm{II})]_{\mathrm{T}}$ can be shown as

$[\operatorname{Pd}(\mathrm{II})]_{\mathrm{T}}=\left[\mathrm{C}_{1}\right]+\left[\mathrm{C}_{2}\right]+\left[\mathrm{C}_{3}\right]+\left[\mathrm{C}_{4}\right]$ Eq. (10)

On substituting the value of $\left[\mathrm{C}_{2}\right],\left[\mathrm{C}_{3}\right]$ and $\left[\mathrm{C}_{4}\right]$, we get

$$
\begin{aligned}
= & {\left[\mathrm{C}_{1}\right]+\mathrm{K}_{1}\left[\mathrm{C}_{1}\right]\left[\mathrm{Cl}^{-}\right]+\mathrm{K}_{1} \mathrm{~K}_{2}[\mathrm{NBP}]\left[\mathrm{C}_{1}\right]\left[\mathrm{Cl}^{-}\right] } \\
& \mathrm{K}_{1} \mathrm{~K}_{2} \mathrm{~K}_{3}[\mathrm{NBP}]\left[\mathrm{C}_{1}\right]\left[\mathrm{Cl}^{-}\right]
\end{aligned}
$$

$\left[\mathrm{H}^{+}\right]$

$$
\left[\mathrm{C}_{1}\right]=\frac{[\mathrm{Pd}(\mathrm{II})]_{\mathrm{T}}\left[\mathrm{H}^{+}\right]}{\left[\mathrm{H}^{+}\right]+\mathrm{K}_{1}\left[\mathrm{Cl}^{-}\right]\left[\mathrm{H}^{+}\right]+\mathrm{K}_{1} \mathrm{~K}_{2}[\mathrm{NBP}]\left[\mathrm{Cl}^{-}\right]\left[\mathrm{H}^{+}\right]+\mathrm{K}_{1} \mathrm{~K}_{2} \mathrm{~K}_{3}[\mathrm{NBP}]\left[\mathrm{Cl}^{-}\right]}
$$

Substituting the value of $\left[\mathrm{C}_{1}\right]$ i.e. $\left[\mathrm{PdCl}_{2}\right]$ in Eqs. (8) we have Eq. (12)

$$
\text { Rate }=\frac{2 \mathrm{kK}_{1} \mathrm{~K}_{2} \mathrm{~K}_{3}[\mathrm{NBP}][\mathrm{Pd}(\mathrm{II})]_{\mathrm{T}}\left[\mathrm{Cl}^{-}\right]}{\left[\mathrm{H}^{+}\right]+\mathrm{K}_{1}\left[\mathrm{Cl}^{-}\right]\left[\mathrm{H}^{+}\right]+\mathrm{K}_{1} \mathrm{~K}_{2} \mathrm{~K}_{3}[\mathrm{NBP}]\left[\mathrm{Cl}^{-}\right]}
$$

Eq. (12) is the rate law on the basis of which observed kinetic orders with respect to each reactants of the reaction can very easily be explained.

On reversing Eq. (12), we have Eq. (13)

$$
\frac{[\mathrm{Pd}(\mathrm{II})]_{\mathrm{T}}}{\text { Rate }}=\frac{\left[\mathrm{H}^{+}\right]}{2 \mathrm{kK}_{1} \mathrm{~K}_{2} \mathrm{~K}_{3}[\mathrm{NBP}][\mathrm{Cl}]}+\frac{\left[\mathrm{H}^{+}\right]}{2 \mathrm{kK}_{2} \mathrm{~K}_{3} \quad[\mathrm{NBP}]}+\frac{1}{2 \mathrm{k}}
$$

Eq. (13), indicates that if a plot is made between $\left.[\mathrm{Pd}(\mathrm{II})]_{\mathrm{T}}\right] /$ rate and $1 /[\mathrm{NBP}]$ or $\left[\mathrm{H}^{+}\right]$or $1 /[\mathrm{KCl}]$ a straight line with positive intercept on $y$-axis will be obtained. Straight line with positive intercepts on $y$-axis obtained by the plots of $\left.[\mathrm{Pd}(\mathrm{II})]_{\mathrm{T}}\right] /$ rate $v s 1 /[\mathrm{NBP}],\left[\mathrm{H}^{+}\right], 1 /[\mathrm{KCl}]$ (Fig. 5) on one hand proves the validity of the rate law (12) and on the other hand the proposed reaction scheme, on the basis of which the rate law (12) has been derived. From the values of intercepts and slopes of the plots, the values of $\mathrm{k}, \mathrm{K}_{1}, \mathrm{~K}_{2} \mathrm{~K}_{3}$ and $\mathrm{K}_{1} \mathrm{~K}_{2} \mathrm{~K}_{3}$ have been calculated and found as $2.45 \times 10^{-2} \mathrm{~s}^{-1}, 1.73 \mathrm{x}$ $10^{3} \mathrm{~mol}^{-1} 1 ., 1.89 \times 10^{2}$ and $3.26 \times 10^{5} \mathrm{~mol}^{-1} 1$ respectively for the oxidation of valine. Utilizing these values of the constants the reaction rate were calculated for the variations of $[\mathrm{Pd}(\mathrm{II})],\left[\mathrm{H}^{+}\right]$. Almost the same values of two rates, i.e. the calculated and observed, further proves the validity of the rate law (12) and hence the proposed reaction scheme.

\subsection{Effect of Ionic Strength \& Dielectric Constant of the Medium}

The ionic strength (I) of the medium on the reaction rate has been described according to the theory of Bronsted and Bjerrum [48], which postulates the reaction through the formation of an activated complex. According to this theory, the effect of ionic strength on the rate for a reaction involving two ions is given by the relationship:

$\log \mathrm{k}_{1}=\log \mathrm{k}_{0}+1.02 \mathrm{Z}_{\mathrm{A}} \mathrm{Z}_{\mathrm{B}} \mathrm{I}^{1 / 2}$.

where $Z_{A}$ and $Z_{B}$ are the valence of the ions $A$ and $B, k_{1}$ and $\mathrm{k}_{0}$ are the rate constant in the presence and absence of the added electrolyte respectively. A plot of $\log \mathrm{k}_{1}$ against $\mathrm{I}^{1 / 2}$ should be linear with a slope of $1.02 \mathrm{Z}_{\mathrm{A}} \mathrm{Z}_{\mathrm{B}}$. If $\mathrm{Z}_{\mathrm{A}} \mathrm{Z}_{\mathrm{B}}$ have similar signs, the quantity $Z_{A} Z_{B}$ is positive and the rate increases with the ionic strength having positive slope, while if the ions have dissimilar charges, the quantity $Z_{A} Z_{B}$ is negative and the rate would decrease with increase in ionic strength, having negative slope. In the present study, the

\section{$\left[\mathrm{H}^{+}\right] \mathrm{M}$}

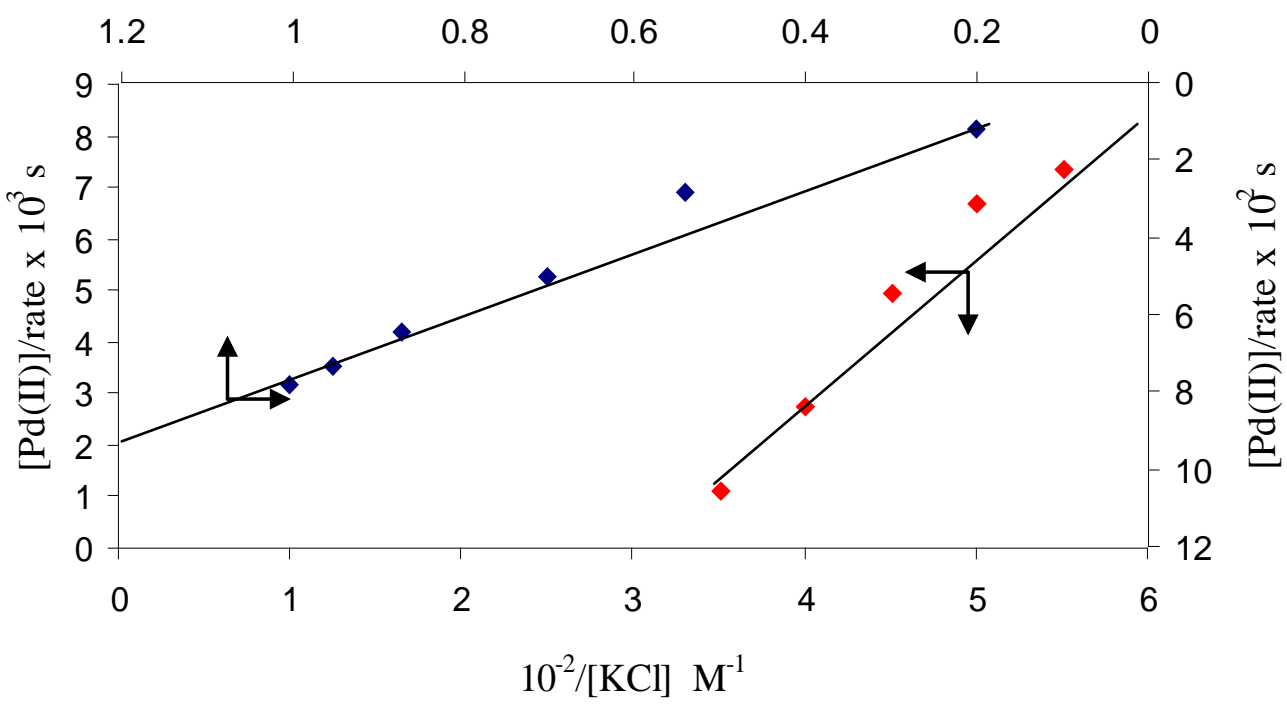

Fig. (5). Plot between $[\mathrm{Pd}(\mathrm{II})] /$ rate $v s\left[\mathrm{H}^{+}\right]$and $1 /[\mathrm{KCl}]$. $[\mathrm{NBP}]=2 \times 10^{-4} \mathrm{M}$, [valine $]=2 \times 10^{-3} \mathrm{M},[\mathrm{Pd}(\mathrm{II})]=4.2 \times 10^{-5} \mathrm{M},\left[\mathrm{Hg}(\mathrm{OAc})_{2}\right]=3$ x $10^{-4} \mathrm{M}$, and $\mathrm{CH}_{3} \mathrm{COOH}=20 \%$. 
ionic strength showed negligible effect on the rate of oxidation, suggesting the involvement of a non-ionic species in the rate determining step.

The change in dielectric constant (D) of the medium has been made by addition of acetonitrile to the reaction mixture. It was found that no reaction of the solvent occurs with the oxidant under experimental conditions. It is clear from the Table 2 that, rate constant values almost constant with the decreasing in $\mathrm{D}$ of the medium also supports the validity of reaction scheme.

In the present study, acetonitrile was used to study the effect of dielectric constant of the medium by varying the solvent composition. It is necessary to verify whether acetonitrile is oxidized by NBP under our experimental condition or not? In order to ascertain the real role of acetonitrile few experiments were performed by taking acetonitrile as organic substrate in place of valine under our experimental condition and it has been found that the acetonitrile is not oxidized by NBP. Thus, the observed rate of reaction with the addition of acetonitrile in reaction mixture is only due to the change in the dielectric constant of the medium.

\subsection{Role of Entropy of Activation and Other Activation Parameters}

Entropy of activation plays an important role in the case of reaction between ions or between an ion and a neutral molecule or a neutral molecule forming ions. When reaction takes place between two ions of opposite charges, their union will results in a lowering of net charge, and due this some frozen solvent molecules will released with an increase of entropy. But on the other hand, when reaction takes place between two similarly charged species, the transition state will be a more highly charged ion, and due to this, more solvent molecules will be required for separate the ions, leading to a decrease in entropy. On the basis of this information, oxidation of valine in the presence of $\operatorname{Pd}(\mathrm{II})$ chloride observed positive entropy of activation $\left(\Delta \mathrm{S}^{\#}\right)$ very well supports the reaction step shown in proposed scheme, where the most reactive species $\left[\mathrm{PdCl}_{3}(\mathrm{NBP})(\mathrm{OH})\right]^{2-}$, is formed by the interaction of charged species, $\left[\mathrm{PdCl}_{3} \mathrm{NBP}\right]^{-}$and a neutral molecule, $\mathrm{H}_{2} \mathrm{O}$. The proposed mechanism is also supported by the moderate values of energy of activation and other thermodynamic parameters. The fairly high positive values of the free energy of activation and of enthalpy of activation suggest that the transition state is highly solvated. A reaction scheme proposed for the oxidation of valine well supports from the order of frequency factor (A) and values of free energy of activation $\left(\Delta \mathrm{G}^{\sharp}\right)$ for the redox system.

\section{CONCLUSION}

In the light of kinetic observations for the catalytic effect $\operatorname{Pd}(\mathrm{II})$ on the oxidation of valine by NBP has been studied in acidic medium. Oxidation of valine by NBP do not proceed in the absence of catalyst, but it becomes facile in the presence of $\operatorname{Pd}(\mathrm{II})$ catalyst. The reactive species of oxidant and catalyst have been identified. Oxidation products were identified and activation parameters were evaluated. The observed results have been explained by a plausible mechanism and the related law has been deduced. Therefore, it can be concluded that $\mathrm{Pd}(\mathrm{II})$ acts as an efficient catalyst for the oxidation of valine.

\section{ACKNOWLEDGEMENT}

One of us (A. K. Singh) is thankful to UGC, Regional office, Bhopal, M.P., India for Research Project grant.

\section{REFERENCES}

[1] Bachhawat, J. N.; Mathur, N.K. Indian J. Chem., 1971, 9, 1335.

[2] Thiagarajan, V.; Venkatasubramanian, N. Indian J. Chem., 1970, 8, 809 .

[3] Mukherjee, N.; Banerjee, K.K. J. Org. Chem., 1981, 46, 2323.

[4] Das, C.M.; Indrasenan, P. Indian J. Chem., 1986, $25 \mathrm{~A}, 605$.

[5] Saroja, P.; Kandlhkar, S. J. Indian Chem. Soc., 1990, 67, 878.

[6] Singh, A.K.; Chopra, D.; Rahmani, S.; Singh, B. Carbo. Res., 1998, 314, 157.

[7] Singh, A.K.; Singh, V.; Singh, A.K.; Gupta, N.; Singh, B. Carbo. Res., 2002, 337, 345 .

[8] Singh, A.K.; Singh, V.; Rahmani, S.; Singh, A.K.; Singh, B. J. Mol. Catal. A:Chemi., 2003, 197, 91.

[9] Rangappa, K. S.; Raghvendra, M.P.; Mahadevappa, D.S.; Gowda, D.C. Carbo. Res., 1998, 306, 57.

[10] Gowda, B.T.; Damodara, N.; Jyothi, K. Int. J. Chem. Kinet., 2005, 37,572 .

[11] Mukherjee, J.; Banerjee, K.K. J. Org. Chem., 1981, 46, 2323.

[12] Singh, B.; Saxena, B.B.L.; Samant, A.K. Tetrahedron, 1984, 40, 3321 .

[13] Abou Ouf, A.; Walash, M.I.; EI-Ashry, S. J. Drug. Res., 1980, 12, 77.

[14] Abou Ouf, A.; Walash, M.I.; Salem, F. B. Analyst, 1981, 106, 949.

[15] Das, C.M.; Indrasenan, P. Indian J. Chem., 1984, $23 A, 869$.

[16] Joshi, G.K.; Katre, Y.R.; Singh, A.K. J. Surfactant Deterg., 2006, 9, 231 .

[17] Katre, Y.R.; Joshi, G.K.; Singh, A.K. Tenside Surfactant Deterg., 2008, 45, 213.

[18] Yathirajan, H.S.; Raju, C.R.; Mohana, K.N.; Sheena, S.; Padmarajaiah, N. Turk J. Chem., 2003, 27, 571 .

[19] Mushran, S.P.; Tiwari, J.N.; Bose, A.K.; Singh, K. Indian J. Chem., 1978, $16 \mathrm{~A}, 35$.

[20] Gowda, B.T.; Rao, R.V. Indian J. Chem., 1988, 27A, 39.

[21] Bhat, K.R.; Jyothi, K.; Gowada, B.T. Oxid. Commun., 2002, 25, 117.

[22] Singh, S.P.; Singh, A.K.; Singh, A.K. J. Mol. Cat. A: Chem., 2008, 293, 97.

[23] Singh, A.K.; Srivastava, J.; Rahmani S. J. Mol. Catal. A: Chem., 2007, 271, 151 .

[24] Mohanty, R.K.; Das, M.; Das, A.K. Indian J. Chem., 1998, 37(A), 34.

[25] Singh, B.; Singh, A.K.; Singh, D. J. Mol. Catal. A: Chem., 1988, 48, 207.

[26] Singh, A.K.; Negi, Reena; Katre, Y.R. ; Singh S.P. J. Mol. Catal. A: Chem., 2009. (Accepted)

[27] Das, A.K.; Das, M. Indian J. Chem., 1995, 34(A), 866.

[28] Singh, A.K.; Rahmani, S.; Singh, Bharat; Singh, R.K.; Singh, M. J. Phys. Org. Chem., 2004, 17, 249.

[29] Ashish; Singh, S.P.; Singh, A.K.; Singh, B. J. Mol. Catal. A: Chem., 2006, 266, 226.

[30] Ashish; Singh, A.K.; Singh, A.K.; Singh, B. Indian J. Chem., 2004, $43 A, 1645$.

[31] Singh, A.K.; Singh, V.; Ashish; Srivastava, J. Indian J. Chem., 2006, 45A, 599.

[32] Jagdeesh, R.V.; Puttaswamy J. Phys. Org. Chem., 2008, 21, 844858 .

[33] Shukla, A.; Gupta, S.; Upadhyay, S.K. Int. J. Chem. Kinet., 1991, $23,279$.

[34] Bajpai, P.; Shukla.A.; Upadhyay, S.K. Int. J. Chem. Kinet., 1996, $28(5), 29$.

[35] Gupta, M., Upadhyay, S.K. Trans. Met. Chem., 1996, 21, 266.

[36] Shukla, A.; Upadhyay, S.K. Indian J. Chem., 1991, 30A, 154-157.

[37] Henry, P. M. Palladium (II) catalysed Oxidation of Hydrocarbons, D. Reidal Publishing Company:Dordecht, 1980, Vol. 2.

[38] Barkat, M.Z.; EI-Wahab, M.F.A. Anal. Chem., 1954, 26, 1973.

[39] Soloway, S.; Lipschietz, A. Anal. Chem., 1952, 24, 898.

[40] Krishnakumar, V.; Balachandran, V.; Chithambarathanu, T. Spectrochim. Acta, 2005, 62, 918.

[41] Patil, S.; Katre, Y.R.; Singh A.K. Colloids and SurfacesA: Physiochem, Eng. Aspects, 2007, 308, 6. 
[42] Singh, A.K.; Jain, B.; Katre Y.R. Oxid. Commun., 2009, 32 (in press).

[43] Kirsch, A.; Luning, U.; Kruger,U. J. Prakt. Chem., 1999, 341, 649.

[44] Day, J.C.; Govindaraj, N.; McBain, D.S.; Skell, P.S.; Tanko, J.M. J. Org. Chem., 1986, 51, 4959.
[45] Cotton, F. A.; Wilkison, G. Advanced Inorganic Chemistry, $5^{\text {th }}$ ed.; Wiley \& Sons: New-York, 1988,

[46] Elding, L.I. Inorg. Chim. Acta, 1972, 6, 647.

[47] Ayers, G.H. Anal. Chem., 1953, 24, 1622-1627.

[48] Laidler, K. J. Chemical Kinetics, $2^{\text {nd }}$ ed.; McGraw- Hill: NewYork, 1965.

(C) Singh et al.; Licensee Bentham Open.

This is an open access article licensed under the terms of the Creative Commons Attribution Non-Commercial License (http://creativecommons.org/licenses/by$\mathrm{nc} / 3.0 /$ ) which permits unrestricted, non-commercial use, distribution and reproduction in any medium, provided the work is properly cited. 